\title{
A novel approach for Zeolite-based Materials for Gas Sensors
}

\author{
Mr. K. Jegan Mohan, Dr. K. Jagadeesan, Dr. Aravind Yadav, \\ Research Scholar, Allahabad University, \\ Professor \& Head, Civil Dept, Mahendra Engg College, \\ Professor / Environmental dept, Allahabad University,
}

\begin{abstract}
This paper deals with the uses of zeolites and zeolite-based materials for developing gas sensors. The purpose of using zeolites in sensors is usually to improve sensitivity and selectivity by preferential adsorption, in addition, thin films assure a fast response time of the sensor. The compound or cluster sensing towards a gas assembled into the cages or channels of zeolites property of the materials were disussed in this paper. The possibility of these materials is tinted and avenues for further research are suggested.
\end{abstract}

Keywords: Zeolite; gas sensing; guest/host materials; absorption.

\section{Introduction}

Zeolites are composed of a structure of tetrahedral $\mathrm{TO}_{4}$ building units $(\mathrm{T}=\mathrm{Si}, \mathrm{Al}$, etc. $)$. The tetrahedral $\mathrm{TO}_{4}$ units link with each other by distribution of oxygen atoms to form three dimensional crystalline spongy skeletons. The T-O-T links result in a diversity of rings, which are dependable for zeolites' cages and channels of different window sizes. Within the skeleton arrangement, the $\mathrm{Al}^{3+}$ atom at the middle of an $\mathrm{AlO}_{4}$ tetrahedron connects to a adjacent $\mathrm{SiO}_{4}$ tetrahedron by sharing an $\mathrm{O}$ atom, and thus generates a negative framework charge which is balanced by an transferable cation, such as an alkaline or alkaline-earth cation and thus, the property of ion exchange is provided [1]. The purpose of using zeolites in sensors is usually to improve sensitivity and selectivity by preferential adsorption, in addition, thin films assure a fast response time of the sensor. The pore size, the ion conductivity, the adsorption and catalytic selectivity of zeolites can be modified by means of ionexchange with different cations. The pores and the cages with certain window sizes within a zeolite's framework allow a few molecules to pass through and others to be expelled, and result in a molecular sieve effect (Fig.1). Zeolites usually possess one, two or three dimensional channel systems. The window sizes are in the range of 0.3-1.5 nm. For example, FER zeolite has two dimensional channels, 10 oxygen ring channels with 0.54 $\mathrm{nm} \times 0.42 \mathrm{~nm}$ windows and 8 oxygen ring channels with $3.5 \mathrm{~nm} \times 4.8 \mathrm{~nm}$ openings (Fig.2) [2], FAU type zeolite has three dimensional $0.74 \mathrm{~nm}$ channels with 12 oxygen ring windows and supercages of $1-2 \mathrm{~nm}$ of diameter (Fig.3).

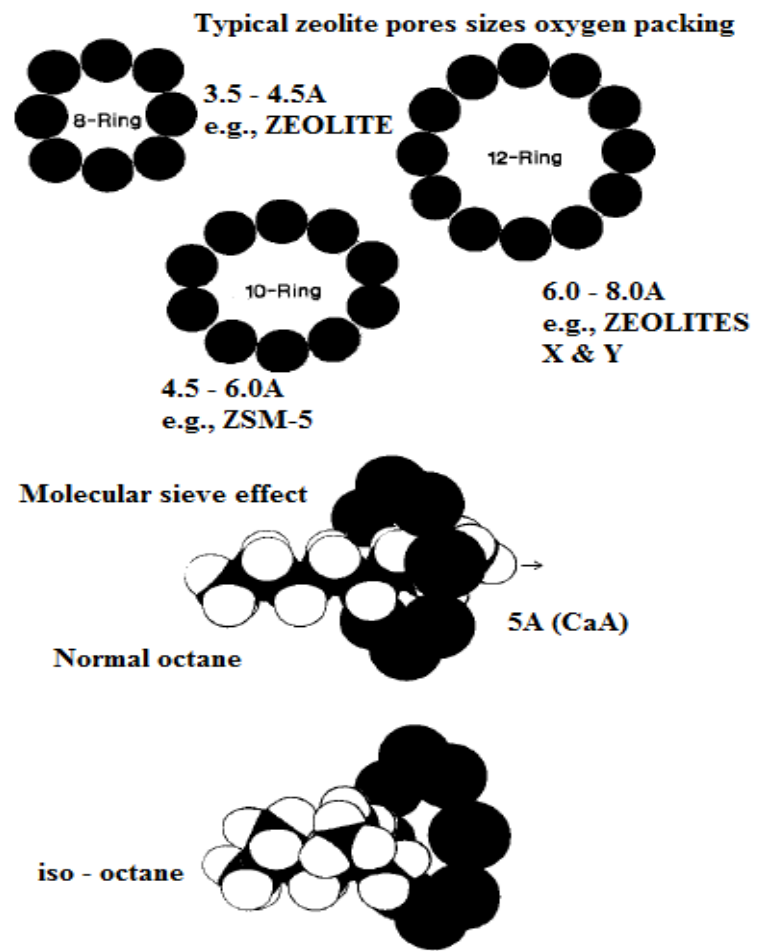

Fig.1. Schematic representation of several typical zeolite windows and the molecular sieve effect. 


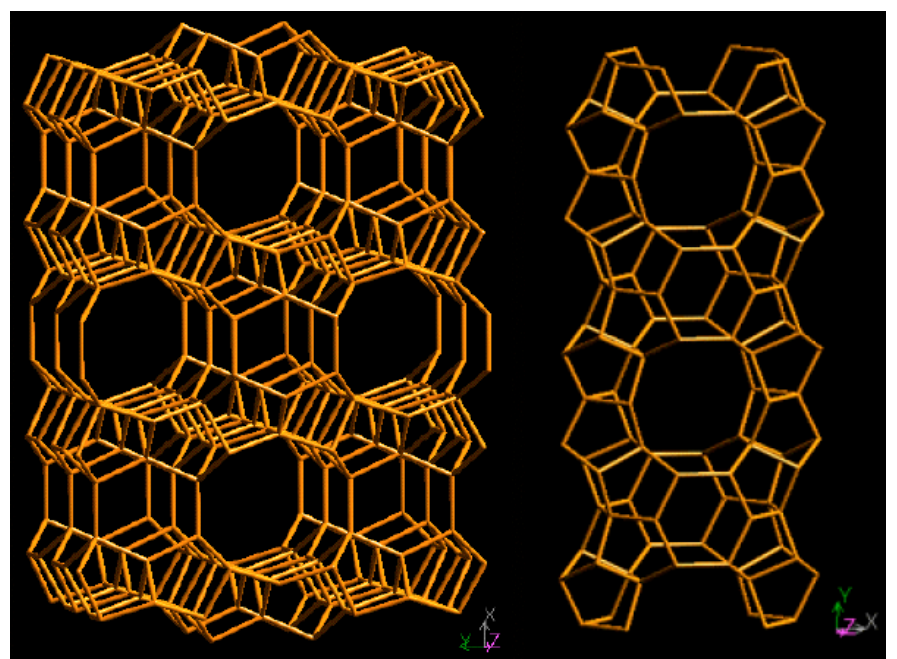

Fig.2. The FER type zeolite framework.

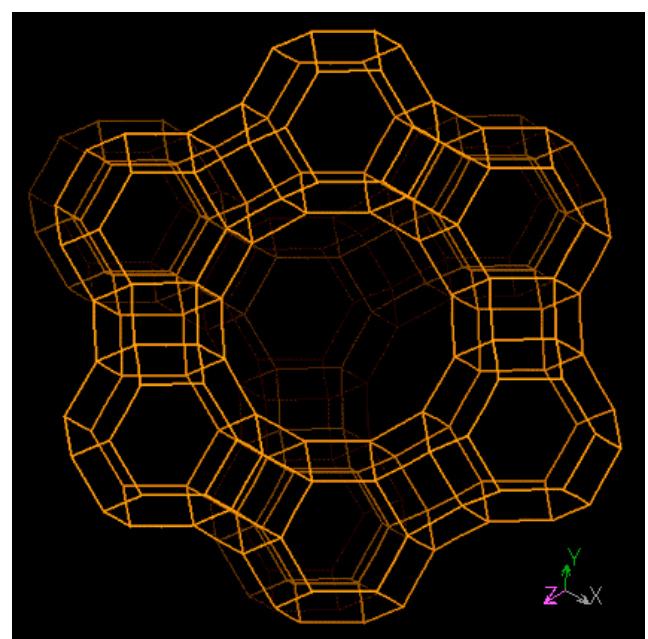

Figure 3. The FAU type zeolite supercage.

The zeolites with low silica contents are hydrophilic, and are typically used as drying agents for absorbing vapor, whereas hydrophobic high siliceous zeolites are used for absorbing organic molecules from moist air or water. When varying the framework $\mathrm{Si} / \mathrm{Al}$ ratio of zeolites greatly changes the adsorption selectivity towards molecules with different polarity. Various applications of zeolite materials in gas sensors have been developed based on the characteristics:

1) Assembly of a compound specifically sensing a gas into zeolite cages or channels, for example, encapsulating ruthenium (II) complexes inside zeolite supercages as an oxygen sensor, inserting methylene blue into zeolites for optical humidity sensing or assembling $\mathrm{LiCl}$ into zeolites as humidity sensors;

2) Fixing of zeolites on quartz crystal micro balances (surfaceacoustic-wave, microcantilever, or optical fiber) for sensing some gases by discriminating absorption;

3) Changing the conductivity of zeolites due to the absorbance of some gases for making sensors based on impedance spectroscopy measurements;

4) Placing zeolites onto sensors as filter materials for enhancing the selectivity to a certain gaseous molecule;

\section{Sensors}

\section{i) $\mathrm{CO}$ and $\mathrm{CO}_{2}$ sensors}

A practical $\mathrm{CO}_{2}$ gas sensor for air quality control has been developed by using a zeolite as a filter material combined with a solid electrolyte of $\mathrm{Na}_{3} \mathrm{Zr}_{2} \mathrm{Si}_{2} \mathrm{PO}_{12}$ (NASICON) and $\mathrm{Li}_{2} \mathrm{CO}_{3}$. The emf of the sensor shows a linear relationship with the logarithm of $\mathrm{CO}_{2}$ concentration. The sensor with zeolite as a filter material minimizes the effect of intrusive gases on the sensor's emf and shows very little deterioration of its response to $\mathrm{CO}_{2}$ [11]. A composite material of FAU type zeolite-Metglas can be used in gas-sensing applications, in which a continuous film of FAU zeolite was synthesized on a Metglas magnetoelastic strip using a secondary growth method. The sensor made of composite presents the ability to remotely sense carbon dioxide in a nitrogen 
atmosphere at room temperature over a wide range of concentrations by monitoring the changes of the resonance frequency on the strip. The zeolite-Metglas composite can also be used as a sensor for a specific gas analyte in a mixture on the condition that the composite possess much higher selectivity of adsorption towards that gas than other components in the mixture [12]. Siliceous FER type zeolite, possessing a prominent ethanolfiltering effect, was coated on a sensing layer of $\mathrm{La}_{2} \mathrm{O}_{3}-\mathrm{Au} / \mathrm{SnO}_{2}$ ceramics for reducing the $\mathrm{C}_{2} \mathrm{H}_{5} \mathrm{OH}$ interference. The sensor based on the ceramic coated with the zeolite presents high selectivity towards $\mathrm{CO}$ among $\mathrm{H}_{2}, \mathrm{CH}_{4}, \mathrm{i}-\mathrm{C}_{4} \mathrm{H}_{10}, \mathrm{C}_{2} \mathrm{H}_{4}$, and $\mathrm{C}_{2} \mathrm{H}_{5} \mathrm{OH}$. As a result, a $\mathrm{CO}$ selective gas sensor was obtained, which has a sensitivity towards $\mathrm{CO}$ over ten times higher than that towards other gases at about 573K [13]. A composite polyaniline/zeolite material can also be used as a $\mathrm{CO}$ sensor [14]. The material exhibits an electrical conductivity response to $\mathrm{CO}$, which is related to the content, pore size and ion exchange capacity of the zeolite, dopant type and concentration. Adding $40 \% \mathrm{w} / \mathrm{w}$ of $\mathrm{NaA}(4 \AA)$ zeolite reduces the electrical conductivity response, but improves the sensitivity towards $\mathrm{CO}$. This concentration is evidently below the percolation

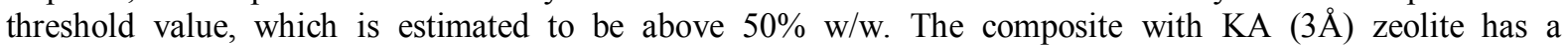
comparable sensitivity value relative to that of pure polyaniline. The composites of both zeolites have greater sensitivity values compared to that of the pure polyaniline in the $16 \sim 1000 \mathrm{ppm} \mathrm{CO}$ concentration range. $\mathrm{CaA}$ $(5 \AA)$ zeolite is the most effective porous material in promoting the interaction among $\mathrm{CO}$ and polyaniline because that zeolite possesses the leading pore size in LTA type zeolite compared with KA and NaA [15].

\section{ii) $\mathbf{O}_{2}$ sensors}

Sensors for detecting and measuring oxygen in gaseous phase or in solution are very important in the field of chemical sensors and biosensors. The zeolite-based materials used for this purpose include the ruthenium (II) bipyridyl complex (Ru2+(bpy)3), which was prepared inside the supercages of a FAU type zeolite, and is an excellent fluorescent oxygen probe. The prepared sensor materials were tested with respect to the quenching of luminescence intensity by molecular oxygen, resulting in measurable responses oxygen. The materials have long-term stability under various conditions with a measuring range of 0-760 Torr, among which the $0 \sim 200$ Torr region presents very good resolution. Both the quenching efficiency and the long-term stability of the Stern-Volmer quenching constant are tremendously improved in comparison with other sensors where the fluorophore is absorbed onto the surface of either a zeolite or silica gel [6]. The highly siliceous zeolitic framework leads to a hydrophobic environment and promotes oxygen transfer from water to the zeolite. The [Ru(bpy)3]2+/highly siliceous FAU zeolite material is a good candidate for use as a dissolved oxygen sensor $[7,8]$. A continuous zeolite film covering the entire sensor surface was designed and prepared on the surface of oxygen sensors, which selectively limits gas exposure on the sensing surface or enriches oxygen. The oxygen is pre-adsorbed (or) entrapped into the zeolite. The results proved that the desirable levels of "oxygenenhancement" had been achieved, and the measurement precision for oxygen containing gases had been improved in these sensors $[9,10]$.

\section{iii) $\mathrm{NH}_{3}$ and amine sensors}

Ammonia gas sensors using proton conductive zeolites and measuring impedance spectroscopy have been developed [16-19]. $\mathrm{NH}_{3}$ promotes the conduction of a proton in $\mathrm{H}$ form in zeolites and increases the specific conductivity proportional to the $\mathrm{NH}_{3}$ concentration, at the same time that it decreases the corresponding activation energy. In order to extend the use of proton conductive zeolites in gas sensing applications, the effects of methylamine and dimethylamine on the proton conductivity were studied in H-ZSM-5 $\left(\mathrm{SiO}_{2} / \mathrm{Al}_{2} \mathrm{O}_{3}=50\right)$ by measuring impedance spectroscopy [16]. A surface plasmon resonance (SPR) sensor with a thin film of LTA type zeolite on a gold surface was prepared via the thiol-alkoxysilane interfacial layers, and investigated by detecting butylamine as a malodorous substance. The anchored zeolite layer was exposed to butylamine, and the shifts of the incident angle (Delta theta) were observed. The Delta theta increased linearly with the gas concentration in the $0 \% \sim 1 \%$ region [20]. The sensitivity depended on the type of zeolites in the order of $13 \mathrm{X}$ zeolite $>5 \AA$ zeolite $\approx$ mordenite $>$ ZSM-5. For detecting ammonia a zeolite-containing coating on a surfaceacoustic-wave (SAW) sensor was used. The frequency of the SAW sensor increases in the reaction of ammonia in a moist atmosphere with the zeolite-containing coating.

\section{iv) $\mathrm{NO}$ and $\mathrm{SO}_{2}$ sensors}

Different types of zeolites, such as zeolite A or silicalite-1 were deposited on one arm of quartz crystal microbalance (QCM) oscillator, and another arm without deposited zeolites was used as the reference. The balance was exposed to a single gas such as $\mathrm{NO}, \mathrm{SO}_{2}$ and $\mathrm{H}_{2} \mathrm{O}$ mixed with $\mathrm{He}$ at $443 \mathrm{~K}$. The frequency shifts and their differential values versus time were measured. Both the shifts and the values were tested to elucidate which was more useful to quantify, and which of these single gases could be used as principal component. Based on these results, mixtures of $\mathrm{NO}$ and $\mathrm{SO}_{2}$ gases in $\mathrm{He}$ of various compositions were examined. The results suggested that the sensor system with the differential values, which represent sorption-kinetics instead of the 
frequency shifts representing sorption-equilibrium, overcame the disadvantages of the conventional QCM sensors and showed favorable qualification and quantification performances for the gas mixtures [22]. A thin layer of FAU type zeolite was synthesized on the QCM with an Au electrode, and applied as a $\mathrm{SO}_{2}$ gas sensor. When $\mathrm{SO}_{2}$ gas molecules are adsorbed on the zeolite layer, the mass increase reduces the frequency of the QCM. The frequency shift of the QCM is proportional to the amount of $\mathrm{SO}_{2}$ adsorbed, resulting in a use for measuring the gas-phase concentration [23]. The NO sensor is based on a potential response to the gas, which is exposed on an electrochemically active interface of yttria stabilized zirconia with a zeolite (YSZ). The zeolite plays the role of promoting the $\mathrm{NO} / \mathrm{NO}_{2}$ equilibrium prior to the gases reaching the interface $[24,25]$. The mixed potential generated is logarithmically related to NO in the concentration range of $0 \sim 1000 \mathrm{ppm}$ at $773 \sim 973 \mathrm{~K}$. The micro porosity of the zeolite makes it permeable to oxygen, thus minimizing the interference of this species.

\section{v) Hydrocarbon and organic molecule sensors}

A quartz crystal microbalance with immobilized ZSM-5 zeolite films has been developed as a sensor for the nerve agent simulant dimethylmethylphosphonate (DMMP) [26]. Frequency shifts related with different concentrations of DMMP were measured. The ambient frequency shift vs time was examined with $1 \mathrm{ppm}, 5$ ppm and $20 \mathrm{ppm}$ of DMMP, respectively. A minimum detectable concentration of $1 \mathrm{ppm}$ DMMP has been obtained in $\mathrm{N}_{2}$ at $293 \mathrm{~K}$. In order to improve the selectivity of the sensor towards DMMP in the presence of other organic gases, zeolite films with different pore size such as MFI type zeolite and $\mathrm{Ag}^{+}$-modified ZSM-5 zeolite were studied. A frequency shift of the films in response to acetone and ethanol at a concentration of 1 ppm were observed. An application of the quartz crystal microbalance modified with $\mathrm{Ag}^{+}-\mathrm{ZSM}-5$ zeolite for detecting acetone in nitrogen was developed [27]. The concentration of acetone in diabetics' breath can be measured. The minimum detectable absorption of acetone vapor was $1.2 \mathrm{ppm}$, and a lower detection limit lower than $0.26 \mathrm{ppm}$ has been identified in the application for the diagnosis of diabetes. Piezoelectric sensor devices (QCM) with $<100 \mathrm{~nm}$ of LTA and BEA type colloidal zeolites were used as micro-sensors for water and organic compounds [28]. The importance of the zeolite's structure type with respect to the sensitivity towards dissimilar organic and water vapors at various concentrations was discussed. In comparison to LTA, the BEA type zeolite film shows a higher sorption capacity towards water vapor and no refusal of pentane, hexane and cyclohexane, due to the superior pore size of the zeolite. A piezoelectric micro-cantilever coated with MFI type zeolite has been developed as a freon gas sensor. Excited by AC voltage, the micro-cantilever was employed to detect the concentration of freon-12 gas in the range of $0 \sim 100 \mathrm{ppm}$ by the modifying effect of the zeolite. High selectivity and sensitivity, combined with excellent repeatable and reversible performances have been exhibited with a linear relationship among the frequency shift in percent and the concentration of freon gas. The minimum mass change of $3.5 \times 10^{-9} \mathrm{~g}$ and the sensitivity of $-0.0024 \% / \mathrm{ppm}$ were determined.

Reversible and monotonic sensor signals were observed with fast responses to the variation of 2propanol concentration in water. However, the sensor responding to pentanoic acid is much slower than that for 2-propanol. Substitution of Si by Al in the MFI framework increased the adsorption of pentanoic acid, resulting in an enhancement of the sensor response. A thin film of polycrystalline silicalite grown on the cleaved end face of a standard single-mode optical fiber has been successfully demonstrated for measuring the concentration of isopropanol vapor in mixtures with nitrogen. ATR (attenuated total reflection) elements coated with silicalite-1 zeolite have been fabricated as a sensor for $n$-hexane. The zeolite film micropores enrich the analyte on the probe surface, and increase the sensitivity. At $6 \times 10^{-5}$ of the relative pressure for $n$-hexane in helium, the sensitivity of the probe for the zeolite coated element is approximately 85 times higher than that of a $10 \mathrm{~cm}$ transmission gas cell, and ca. 180 times higher than that for an uncoated element. The performance of the probe is illustrated by the adsorption isotherm of $\mathrm{n}$-hexane on the zeolite.

$\mathrm{A} \mathrm{Na}^{+}$ion conducting ZSM-5 zeolite was applied as the sensitive phase in a potentiometric gas sensor consisting of the $\mathrm{Au} /\left(\mathrm{Na}_{2} \mathrm{CO}_{3}, \mathrm{BaCO}_{3}\right) /$ zeolite/Au cell, where the $\mathrm{Na}_{2} \mathrm{CO}_{3} / \mathrm{Au}$ system serves as the reference electrode. The cell voltage showed a linear response to the changes of the logarithm of propane partial pressure (200-4000 Pa) in $\mathrm{CO}_{2} / \mathrm{O}_{2} / \mathrm{N}_{2}$ at $673 \mathrm{~K}$. A mechanism was proposed based on the changes of $\mathrm{Na}$ or $\mathrm{Na}^{+}$activity in the zeolite pores due to hydrocarbon sorption. An independent effect is a weak response of the zeolite/Au electrode to $\mathrm{O}_{2}$ and $\mathrm{CO}_{2}$ due to the formation of oxide and carbonate. The FAU type zeolite doped with platinum by ion-exchange has been used as a gas sensitive layer material on thin-film inter-digital capacitors (IDCs). The sensitivity of the zeolite-IDC sensor excited with sinusoidal voltage has been determined on the impedance response for $\mathrm{C}_{4} \mathrm{H}_{10}, \mathrm{CO}$ and $\mathrm{H}_{2}$ in wet air.A P-type semiconductor family of $\mathrm{SrTi}_{1-\mathrm{x}} \mathrm{Fe}_{\mathrm{x}} \mathrm{O}_{3}$-delta with a perovskite structure has been used as the base material for a hydrocarbon sensor. A cover layer made of platinum-doped zeolite with catalytica activity has been proven to have an effect for reducing the crossinterference influence of some species. An initial model for explaining the sensing mechanism was proposed. In order to advance the selectivity of metal oxide sensors, zeolites modified with chromium were used to control the selectivity to alkanes based on shape and size effects. 
Gas sensors of Pd-doped $\mathrm{SnO}_{2}$ semiconductor covered with zeolitic films (MFI or LTA type) have been prepared and used for detecting different species at different humidity levels. The dynamic responses accessible by these sensors were compared with that of a reference sensor without the zeolitic layer. The results clearly indicated that a suitable zeolite layer strongly reduces the response of the sensor to paraffins. Thereby, the sensor selectivity towards alcohol increases, while the reference sensor could not classify between these molecules. This clearly shows the potential of zeolite-based sensors for achieving a higher selectivity/sensitivity in gas sensing applications.

\section{Conclusions}

The zeolite-based materials used in gas sensors have received great attention. The high and selective absorption properties of zeolites towards a specific gas deeply enhance the sensing selectivity for the gas. The compound or cluster sensing towards a gas assembled into the cages or channels of zeolites results in its high stability, and maximally raise the sensing property of the materials. The application of composite materials partially composed of a zeolite, opens new ways for choosing gas sensor materials as well. However, much more works remains to be done. Overall, we predict that zeolites will become broadly available materials for gas sensing material.

\section{References}

[1]. Breck, D.W. Zeolite Molecular Sieves, Chemistry and Use; Wiley: New York, USA, 1974.

[2]. Baerlocher, Ch.; Meier, W.M.; Olson, D.H. Atlas of Zeolite Framework Types. 5th ed.; Elsevier:London, 2001

[3]. Valdés Granda, M.; Pérez-Cordoves, A.I.; Díaz-García, M.E. Zeolites and zeolite-based materials in analytical chemistry. TracTrends Anal. Chem. 2006, 25, 24-30.

[4]. Coronas, J.; Santamaria, J. The use of zeolite films in small-scale and micro-scale applications.Chem. Eng. Sci. 2004, 59, 48794885 .

[5]. Simon, U.; Franke, M.E. Electrical properties of nanoscaled host/guest compounds. Microporous Mesoporous Mat. 2000, 41 , 1-36.

[6]. Meier, B.; Werner, T.; Klimant, I.; Wolfbeis, O.S. Novel oxygen sensor material based on a ruthenium bipyridyl complex encapsulated in zeolite-Y-dramatic differences in the efficiency of luminescence quenching by oxygen on going, from surfaceadsorbed to zeolite-encapsulated fluorophores. Sensor. Actuator. B-Chem. 1995, 29, 240-245

[7]. Payra, P.; Dutta, P.K. Development of a dissolved oxygen sensor using tris(bipyridyl) ruthenium (II) complexes entrapped in highly siliceous zeolites. Microporous Mesoporous Mat. 2003, 64,109-118.

[8]. Coutant, M.A.; Payra, P.; Dutta, P.K. Oxygen transport in zeolite Y measured by quenching of encapsulated tris(bipyridyl)ruthenium. Microporous Mesoporous Mat. 2003, 60, 79-90.

[9]. Lin, L.; Guthrie, J.T. Novel oxygen-enhanced membrane assemblies for biosensors. J. Membr.Sci. 2006, 278, 173-180.

[10]. Rauch, W.L.; Liu, M. Development of a selective gas sensor utilizing a perm-selective zeolite membrane. J. Mater. Sci. 2003, 38, 4307-4317.

[11]. Kaneyasu, K.; Otsuka, K.; Setoguchi, Y.; Sonoda, S.; Nakahara, T.; Aso, I.; Nakagaichi, N. A carbon dioxide gas sensor based on solid electrolyte for air quality control. Sensor. Actuator BChem.2000, 66, 56-58.

[12]. Giannakopoulos, I.G.; Kouzoudis, D.; Grimes, C.A.; Nikolakis, V. Synthesis and characterization of a composite zeolite-metglas carbon dioxide sensor. Adv. Funct. Mater. 2005, 15, 1165-1170.

[13]. Fukui, K.; Nishida, S. CO gas sensor based on Au-La2O3 added SnO2 ceramics with siliceous zeolite coat. Sensor. Actuator BChem. 1997, 45, 101-106.

[14]. Densakulprasert, N.; Wannatong, L.; Chotpattananont, D.; Hiamtup, P.; Sirivat, A.; Schwank, J. Electrical conductivity of polyaniline/zeolite composites and synergetic interaction with CO.Mater. Sci. Eng. B-Solid State Mater. Adv. Technol. 2005, 117, 276-282.

[15]. Chuapradit, C.; Wannatong, L.R.; Chotpattananont, D.; Hiamtup, P.; Sirivat, A.; Schwank, J. Polyaniline/zeolite LTA composites and electrical conductivity response towards CO. Polymer 2005, 46, 947-953.

[16]. Rodriguez-Gonzalez, L.; Franke, M.E.; Simon, U. Electrical detection of different amines with proton-conductive H-ZSM-5. Stud. Surf. Sci. Catal. 2005, 158, 2049-2056.

[17]. Franke, M.E.; Simon, U.; Moos, R.; Knezevic, A.; Muller, R.; Plog, C. Development and working principle of an ammonia gas sensor based on a refined model for solvate supported proton transport in zeolites. Phys. Chem. Chem. Phys. 2003, 5, 5195-5198.

[18]. Moos, R.; Muller, R.; Plog, C.; Knezevic, A.; Leye, H.; Irion, E.; Braun, T.; Marquardt, K.J.;Binder, K. Selective ammonia exhaust gas sensor for automotive applications. Sensor. Actuator.B-Chem. 2002, 83, 181-189.

[19]. Simon, U.; Flesch, U.; Maunz, W.; Muller, R.; Plog, C. The effect of NH3 on the ionic conductivity of dehydrated zeolites Na beta and $\mathrm{H}$ beta. Microporous Mesoporous Mat. 1998, 21,111-116.

[20]. Arakawa, T.; Kawabayashi, A.; Saga, T. Detection of butylamine by means of surface Plasmon resonance. Sensor. Actuator. BChem. 2005, 108, 899-902.

[21]. Shul'ga, A.A.; Zuev, B.K.; Lontsov, V.V. Zeolite-containing sensitive coatings for surfaceacoustic-wave chemical gas sensors. J. Anal. Chem. 1999, 54, 449-454.

[22]. Sasaki, I.; Tsuchiya, H.; Nishioka, M.; Sadakata, M.; Okubo, T. Gas sensing with zeolite-coated quartz crystal microbalancesprincipal component analysis approach. Sensor. Actuator. B-Chem.2002, 86, 26-33.

[23]. Osada, M.; Sasaki, I.; Nishioka, M.; Sadakata, M.; Okubo, T. Synthesis of a faujasite thin layer and its application for SO2 sensing at elevated temperatures. Microporous Mesoporous Mat.1998, 23, 287-294.

[24]. Szabo, N.F.; Dutta, P.K. Strategies for total NOx measurement with minimal CO interference utilizing a microporous zeolitic catalytic filter. Sens. Actuator B-Chem. 2003, 88, 168-177.

[25]. Szabo, N.F.; Du, H.B.; Akbar, S.A.; Soliman, A.; Dutta, P.K. Microporous zeolite modified yttria stabilized zirconia (YSZ) sensors for nitric oxide (NO) determination in harsh environments.Sens. Actuator B-Chem. 2002, 82, 142-149.

[26]. Xie, H.F.; Yang, Q.D.; Sun, X.X.; Yu, T.; Zhou, J.; Huang, Y.P. Gas sensors based on nanosizedzeolite films to identify dimethylmethylphosphonate. Sens. Mater. 2005, 17, 21-28. 